\title{
LABORATORY MODELLING AND ACOUSTIC DIAGNOSTICS OF HYDRODYNAMICAL PROCESSES
}

\author{
VLADIMIR CHERNOV
}

\author{
Institute of Applied Physics, RAS \\ 46 Ulyanov str., Nizhny Novgorod, 603950, Russia \\ vcher@appl.sci-nnov.ru
}

In the present paper results of modelling of wind interaction with a water layer surface and research of the vortical structures arising downstream the flow around bodies are described. Results of the use of the method of acoustic diagnostics of spatially-periodic vortical flows are presented. At physical modelling in laboratory conditions wind was created with a low-velocity wind tunnel. The structure of an air stream and convective cells on water surface was investigated with the help of visualization. Some pictures of structures on the shallow sea surface are also demonstrated and discussed.

\section{INTRODUCTION}

Study of interaction of wind with ocean surface is important as for understanding of heat exchange between the ocean and the atmosphere, and for interpretation of radar and visual pictures of the ocean surface. The important role for this plays thin subsurface water layer.

A large amount of experimental observations of a near-surface layer in different water basins (including the ocean, seas and lakes) showed that in many cases the water surface is colder compared to the bulk [1]. The cooling of water surface due to evaporation gives rise to the formation of a thermal boundary layer having the scale of about one millimeter which is frequently termed 'a cold liquid film' [1]. The inverse temperature distribution can give rise to the convective instability which usually develops in the presence of a wind-driven flow. The convective instability is one of possible causes of the Langmuir circulations in natural water basins, which are associated with roll-like vortex, structures elongated in the direction of the wind [2]. Besides, interaction of wind with sea surface produces vortices in the water and in the air. However it is extremely difficult to study such processes in the ocean. 
Numerical simulation of the roll convection caused by evaporation was performed mainly for the sea conditions (e.g, [2,3]). In this work the convective (Rayleign-Benard) instability in the liquid layer affected by evaporation and tangential wind stresses is studied from the viewpoint of the nonlinear dynamics, i.e., attention is focused on the peculiarities of structure development. The laboratory experiment is performed with heated silicon oil and a well-evaporating liquid (alcohol) and a two-dimensional theoretical model corresponding to the experimental conditions is constructed.

Currently, laboratory remote acoustic diagnostics of vortical and temperature pulsations in air flows has been carried out for a number of well studied flows: the Karman vortex street behind a round cylinder [4-6], vortex rings [7], vortices behind a heated body [8], buoyant thermic [9], and heated jet [10]. These experiments have established the parameters of hydrodynamic flows, which can be determined by the characteristics of scattered sound. The experimental concept was that data obtained for flows with controlled parameters were to be compared to a calculation carried out within the models described by a small number of parameters: vortex circulation, vortex motion velocity, and quantity of heat transferred by vortices. The flows studied were actually laminar.

Laboratory acoustic diagnostics, making it possible to control all the parameters of flows, can be efficient in the simulation of acoustic sounding of the atmosphere and water reservoirs. However, to compare laboratory and field experimental data on acoustic diagnostics of the atmosphere [11], scattering at more complex flows is to be studied.

The laminar flow was accompanied by systematic vortex separations, as well as Karman streets behind cylinder. In the turbulent mode, the flow consists of a large number of randomly arranged vortices. Thus, for more full research of a vortical Karman street behind the heated up cylinder we have executed experiments on visualization and remote acoustic diagnostics of vortical current. Earlier it was found that topological defects may arise in a wake behind a heated cylinder [18] as vortex merging that results in the loss of one spatial period. To control twodimensional flows, a method of acoustic diagnostics was developed that allows one to detect topological defects in a periodic street by spectra of the scattered sound [19].

\section{MODELLING OF CONVECTIVE PROCESSES}

A rectangular, cavity filled with alcohol is allocated in the plate of organic glass. The plate is placed in the operating part of the low-turbulence wind tunnel. For the flow visualization the light-reflecting powder is used. After impeller of the wind tunnel is switched on, the wind velocity $V_{o}$ reaches quickly (in the time less than 1 minute) a steady value within the $1.5-2.5 \mathrm{~m} / \mathrm{s}$ range and a turbulent boundary layer is formed over the cavity. The measured thickness of the boundary layer is equal approximately to $2 \mathrm{~cm}$.

The velocity of the wind-driven flow increased progressively to its steady value (which is about $2.5 \mathrm{~cm} / \mathrm{s}$ ). Top view of the flow structure in the cavity is presented in Fig. 1,a. A sequence of visualization pictures arising with growing wind velocity is displayed in Figs. 1,b-d. Figure 1,b shows the hexagon-like structures which were observed without wind blowing. Figure 1,c demonstrates the effects of enlargement of the hexagons and their elongation in the direction of the wind at fairly small wind velocity. When the wind velocity approaches its steady value, the system of black and white strips corresponding to the roll convection in the liquid layer appears on the surface (Fig. 1,d). 

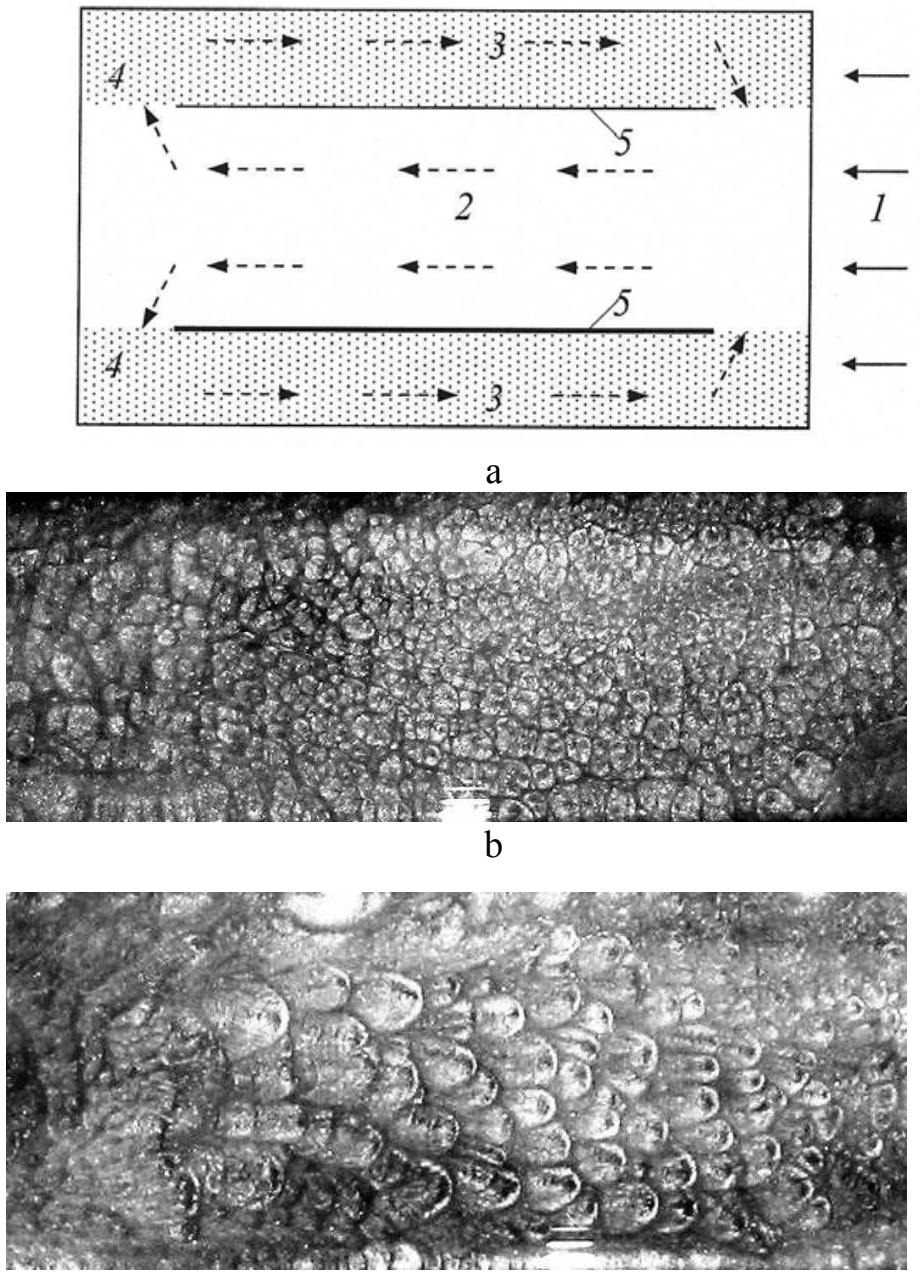

$\mathrm{C}$

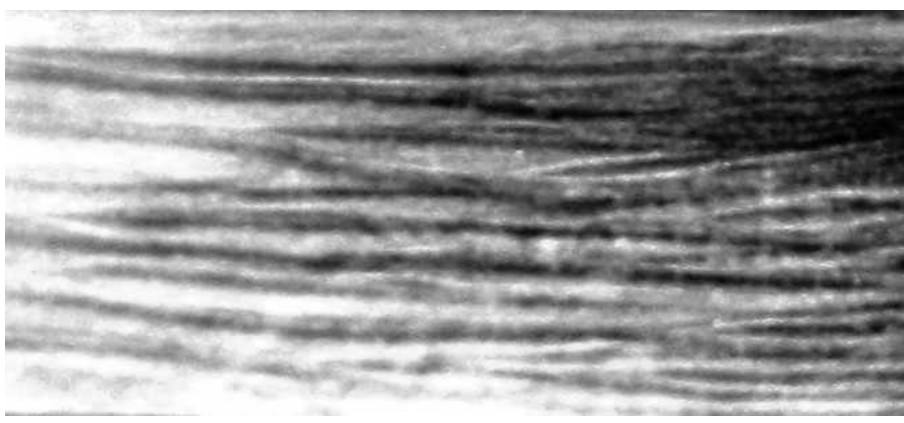

d

Fig.1 Sketch of the experimental setup (a) and images of the fluid surface for immovable air (b), immediately after starting of the wind blowing (c), and at the steady wind velocity $V_{o}=1.5 \mathrm{~m} / \mathrm{s}(\mathrm{d})$. Designations in (a) are 1 - forward air flow, 2 (dashed arrows) - wind-driven fluid flow, 3 (dashed arrows) - counter fluid flow, 4 (shaded fields) - horizontal screens above the counter flow, 5 vertical screens delimiting the accompanying and counter flows 
Similar experiments were carried out with $0.4 \mathrm{~cm}$ silicon oil layer heated from below. In absence of wind above liquid surface $(\mathrm{V}=0)$ at excess of critical value of temperature difference convection arises. A picture of convective cells obtained for bottom temperature $50^{\circ} \mathrm{C}$ is shown in Fig. 2. After turning on wind tunnel wind stress on silicon oil surface produces shear current in liquid that results in increase of convective cell size and their drift in the direction of air stream $(\mathrm{V}=12 \mathrm{~cm} / \mathrm{c})$. Thus, characteristic spatial period of cells increases in wind direction. At excess of critical value of stream velocity cellular convection is changed by convective rolls which axes are directed along the wind $(\mathrm{V}=160 \mathrm{~cm} / \mathrm{c})$. At higher wind velocities convective rolls contain a numerous defects.

Hence wind stresses on liquid surface generate shear flow in thin liquid layer that changes convection structure.

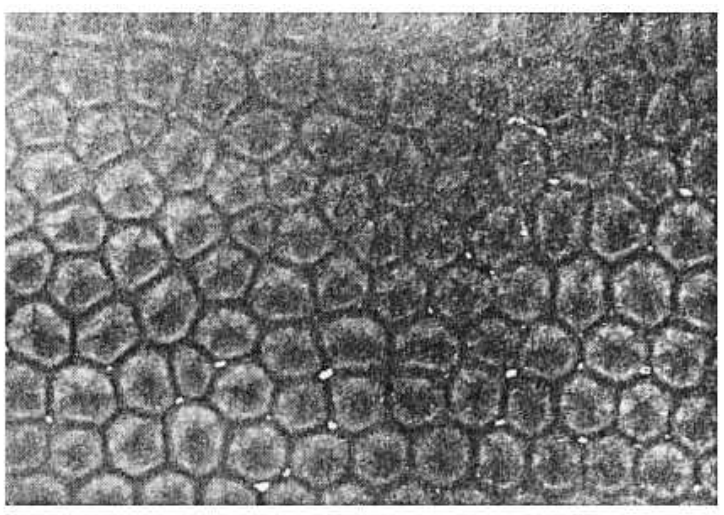

a

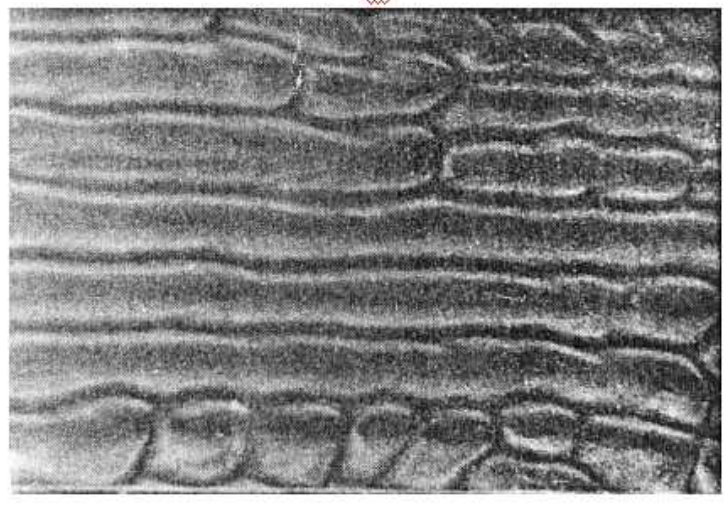

C

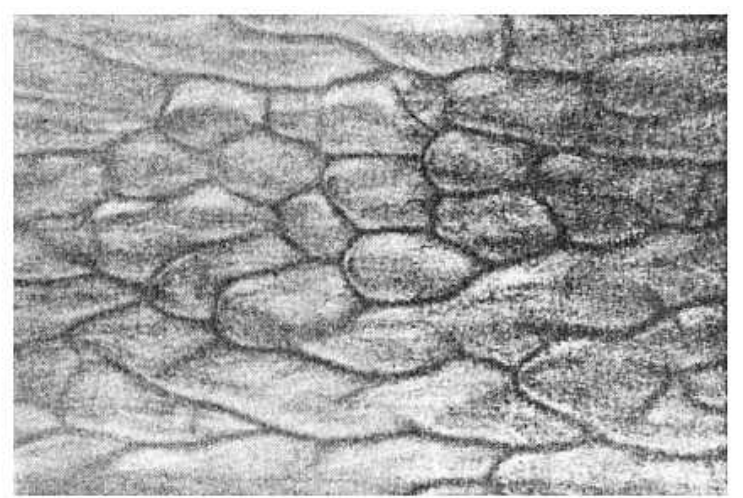

b

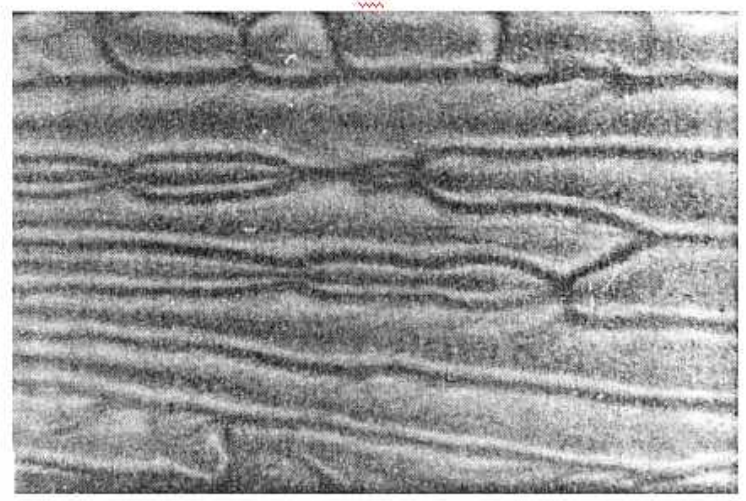

$\mathrm{d}$

Fig.2 Photo images of the silicon oil heated from below for immovable air (a), immediately after starting of the wind blowing $(\mathrm{b}, \mathrm{V}=12 \mathrm{~cm} / \mathrm{c})$, and at the steady wind velocity $V_{o}=160 \mathrm{~cm} / \mathrm{s}(\mathrm{c})$, and $180 \mathrm{~cm} / \mathrm{c}(\mathrm{d})$

The similar phenomenon - occurrence of roll structure Woodcock observed on water surface in narrow straits, bays and on a surface of long waves at the high sea states [12]. We also observed similar structures on surface of the "Nizhny Novgorod sea" (a reservoir at Volga river). Corresponding picture is presented in Fig. 3. It was obtained in solar weather at $25^{\circ} \mathrm{C}$ and at weak extended along wind direction, the spatial period of rolls is a few centimeters. More detailed 
description of experiment and the theoretical analysis are given in [13-14].

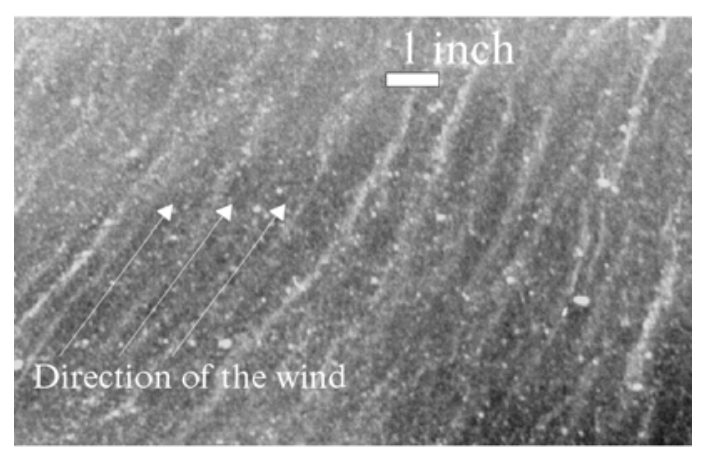

Fig.3 The roll structure on the surface of the "Nizhny Novgorod sea"

\section{ACOUSTIC DIAGNOSTICS OF VORTICAL STRUCTURES}

This part of the work is devoted to studying of vortical flows in air by means of the acoustic diagnostic method. The main attention is paid to investigation of vortical flows behind a heated cylinder - influence of heating on characteristics of vortical structure. The experimental setup is similar to that in [15]. As the cylinder a nickel-chrome alloy wire of $0.6 \mathrm{~mm}$ diameter was used. It was heated from a source of the direct current. The temperature of the cylinder can be estimated on the known heat transfer expression established empirically for the round cylinders [16]: $N u=0.36 \sqrt{\operatorname{Re}}+0.057 \sqrt[3]{\operatorname{Re}^{2}}$ and was equal $T_{C}-T_{\infty}=\Delta T=Q / \pi \cdot L \cdot \lambda_{0} \cdot N u(\operatorname{Re})$, where $Q$ - quantity of heat in Joules generated in the cylinder by the direct electrical current, $L$ length of the cylinder, $\lambda_{0}$ - heat conductivity of gas at temperature of a air stream. Reynolds's number of an accumulating stream was equaled $\mathrm{Re}=81$, and Reynolds's effective number changed in a range $35<\mathrm{Re}_{\text {eff }}<81$.

A piezoceramic sound source was placed behind a screen with a square hole $(2 \times 2 \mathrm{~cm})$. The source was placed $65 \mathrm{~cm}$ apart from the Karman's street center for the Fraunhofer approximation to be satisfied $D_{F} \approx \Lambda^{2} / \lambda=30 \mathrm{~cm}$, where $\Lambda$ is the source size. The radiator settled down under angle $40^{0}$ to the normal to air flow.

The periodic vortical street was observed downstream behind the cylinder. To measure parameters the received ultrasound we used a high-frequency $4135 \mathrm{~B} \& \mathrm{~K}$ microphone. Signal was transferred into the frequency range $0-20 \mathrm{kHz}$ by heterodyning. The microphone was placed 1.6 $\mathrm{m}$ apart from the vortex street. It position varied in the angular range from $45^{\circ}$ to $-45^{\circ}$ with respect to the direction to the ultrasound source. The spectral characteristics of the scattered signal were measured using a computer.

Angular dependence of sound scattered by the vortex street (that is the moving periodic grid) represents a few number of angular maxima and minima, which correspond to spatial harmonics of scattered sound field. During experiments it was measured time spectra of the 1-st spatial harmonic of scattered sound for several temperatures of the cylinder. Measurements were 
carried out as follows: for each temperature of the cylinder first of all it was found the angle of the 1-st spatial harmonics (maximum of amplitude), and then the time spectrum of signal was registered and analyzed. Increase of the cylinder temperature resulted in the downshift of vortex frequency that was also observed in [17]. The obtained data are shown in Fig. 4. It is seen from the figure that in the definite range of temperatures of the cylinder some asymmetry in the spectrum arises. Below and above of this temperature range spectra are symmetric. This asymmetry is similar to that was observed in [17] in a spectrum of pulsations of a field of temperature.

In experiments we also used visualization of a vortical street at various temperatures of the cylinder. Visualization was carried out by means of a thin wire of $0.2 \mathrm{~mm}$ which was stretched parallel to the basic cylinder at distance of $\sim 9 d$ downstream. The wire was covered by oil and electrical current through it was turned on. Smoke from the wire made it possible the visualization of vortical trace. Pictures was done by means of a digital camera (Fig. 5). From figure 5 one can see defects in vortical street. At the photo the basic cylinder and a visualizing wire are located on the right side, the air flow is directed from right to left, and the distance from the cylinder to the left side of picture is $\sim 200 d$. It is necessary to note, that without heating axes of vortexes have some vertical angle relatively the basic cylinder, while during heating axes of vortexes are parallel to the axis of the basic cylinder. Thus, even small heating $\left(\Delta T=155^{\circ} \mathrm{C}\right)$ resulted in "ordering" a vortical street. For temperatures above $\Delta T=308^{\circ} \mathrm{C}$ large-scale defects start to be observed. At $\Delta T=434^{\circ} \mathrm{C}$ a number of defects such as «pulses of blackout» are observed up to the temperature $\Delta T=480^{\circ} \mathrm{C}$. Further increase in heating results in ordered vortical street again with axes parallel to the cylinder. At the maximal heating, $\Delta T=665^{\circ} \mathrm{C}$ a vortical street is not observed any more, since $\operatorname{Re}_{e f f}<\mathrm{Re}_{c}$ (where $\mathrm{Re}_{c}$ - Reynolds's critical number at which there is a periodic vortex street). In this case there are only low-frequency pulsations caused, apparently, by the convective instability of the heated air. Defects in vortical street are responsible for asymmetry of spectra in figure 4.

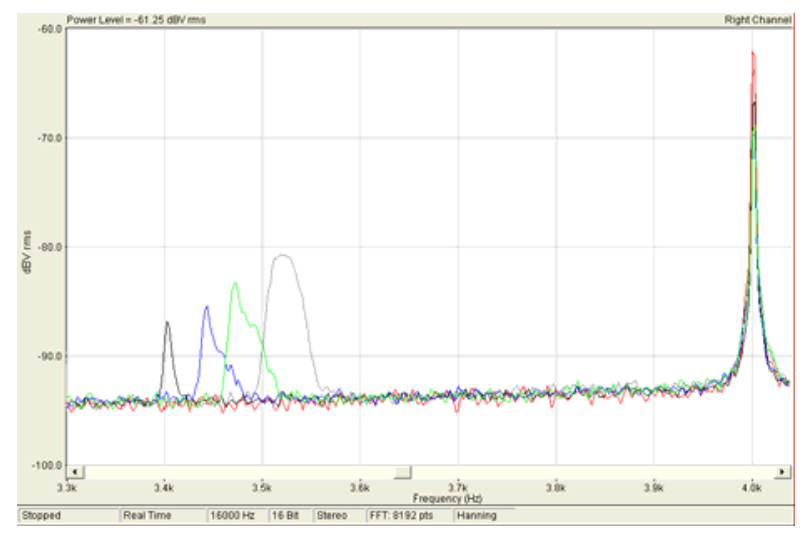

Fig.4 Spectra of the scattered sound

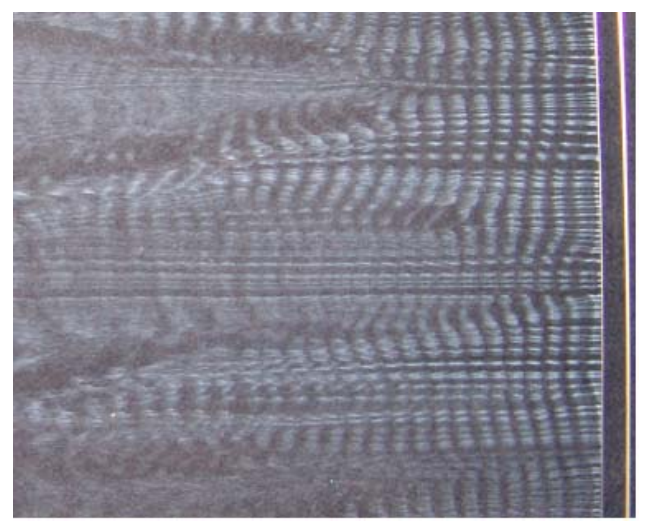

Fig.5 Visualization of a vortical trace 


\section{CONCLUSION}

Метод физического моделирования использовался в данной работе для исследования особенностей термоконвекции в верхнем слое моря. Термоконвекция обусловлена остыванием тонкой поверхностной пленки воды под действием ветра. Ветровые напряжения в свою очередь приводят к формированию роликовой структуры конвективных течений в отличие от хорошо известной ячеистой структуры конвекции в отсутствие ветра.

The method of physical modelling was used in the given work for research of features of thermoconvection in the upper sea layer. Thermoconvection is caused by cooling of a thin water film under action of wind. Wind stress in turn results in formation of roll structure convective flows as against well-known cellular structure of the convection in absence of wind.

The method of acoustic diagnostics of hydrodynamic vortex flow was demonstrated for the vortical structure generated in an air flow behind of heated cylinder. Experiments have first time shown, that in a vortical street behind the heated cylinder at not too big supercriticallity $\left(\operatorname{Re}_{\text {eff }} \sim 45 \div 55\right)$ and temperatures of heating of the cylinder $\left(300^{\circ}-480^{\circ} \mathrm{C}\right)$ there are defects such as «pulses of blackout». The visualization of vortex flow at the specified parameters has allowed to confirm the existence of these defects, which are related with the density stratification of the vortex flow. Detailed theoretical description of this phenomenon is to be done.

Thus, the method of acoustic diagnostics can be effectively used for investigation of flow structures in gas and liquids.

\section{ACKNOWLEDGEMENT}

The work was done under financial support of the RFBR-CNRS (grant 07-02-92175).

\section{REFERENCES}

1. G.N. Panin. The heat-mass transfer between the basin and atmosphere under natural conditions. Nauka-press, Moskow, 1985 (in Russian).

2. O.V. Emel'anova, A.E. Ordanovich. Vestnik Moskovskogo Universiteta, Ser. 1, Matematika. Mekhanika. 2002, N.3, 36 (in Russian).

3. V.A. Shlychkov. Vichislitelnye Tehnoiogii. 1998, 3, N.6, 97 (in Russian).

4. P. Gromov, A. Ezersky, A. Fabrikant. Sound Scattering on the vortex street from cylinder, Akust. Zh., Vol. 28(6), 763-765, 1982.

5. C. Baudet, S. Giliberto, J. Pinton. Phys. Rev.Lett., Vol. 67(2), 193-195, 1991.

6. A. Ezersky, P. Soustov, V. Chernov. Sound Scattering by Karman street, Acoust. Phys., Vol. 46(6), 764-769, 2000.

7. P. Gromov, A. Ezersky, S. Kiyashko, A. Fabrikant. Preprint No. 59, Inst. Appl. Phys., Gorky, 1982.

8. A. Ezersky, A. Zobnin, P. Soustov. Radiophys. \& Quantum Electronics, Vol. 38(8), 832-839, 1995.

9. J. Pinton, C. Laroche, S. Fauve, C. Baudet. Ultrasound scattering by, buoyancy driven flows, J. Phys. II (Paris), Vol. 7, 767-773, 1993.

10. A. Petrossian, J. Pinton. J. Phys. II (Paris), Vol. 7, 801-812, 1997.

11. V. Rapoport, N. Mityakov, V. Zinichev. Radiophys. \& Quantum Electronics, Vol. 41(7), 241- 
245, 1998.

12. A.H. Woodcock. J. Mar. Res. 1941, V.4, p. 153.

13. A.B. Ezersky, V.V. Chernov. Izv. RAN. Fizika Atmosfery i Okeana. 1999, 35, 656 (in Russian).

14. A.B. Ezersky, V.P. Reutov, G.V. Rybushkina, V.V. Chernov. Simulation of the convective structures in a thin liquid layer in the presence of a winddriven flow. In: Frontiers of Nonlinear Physics, Nizhny Novgorod, 2005, p. 243-247.

15. A. Ezersky, P. Gromov, P. Soustov, V. Chernov, «Acoustic sensing of hydrodynamic vortex flow», Hydroacoustics, 2005, V.8, p.47-52.

16. P. Tchjen. Tearing off currents. M., Mir, 1973 (in Russian).

17. An-bang Wang at all., "On the relationship of effective Reynolds number and Strouhal number for laminar vortex shedding of a heated circular cylinder," Physics of Fluids, Vol. 12, No. 6, June 2006.

18. A.B. Ezersky, P. Paranthoen. Int. J. Transport Phenomena 2005, v.7, p.45.

19. P.L. Soustov, P.R. Gromov, A.B. Ezersky, V.V. Chernov, "Proceedings of the XIX session of the Russian Acoustical Society, Nizhny Novgorod, September 24-28, 2007, v.1, p.115. 